\title{
Surgical Outcomes of Revision Operation for Non-Cholesteatomatous Chronic Otitis Media
}

\author{
Juho Han ${ }^{\mathbb{D}}$, Jisoo Lee, Sung Kwang Hong, Hyo Jeong Lee, and Hyung-Jong Kim (iD \\ Department of Otorhinolaryngology-Head and Neck Surgery, Hallym University College of Medicine, Anyang, Korea
}

비진주종성 만성 중이염의 재수술에 대한 결과 분석

한주호 · 이지수 · 홍성광 · 이효정 · 김형종

한림대학교 의과대학 이비인후-두경부외과학교실

Received December 13, 2019

Revised June 1,2020

Accepted June 8, 2020

Address for correspondence

Hyung-Jong Kim, MD, PhD

Department of Otorhinolaryngology-

Head and Neck Surgery,

Hallym University Sacred Heart

Hospital, 22 Gwanpyeong-ro

170beon-gil, Dongan-gu,

Anyang 14068, Korea

Tel $+82-31-380-3842$

Fax $+82-31-386-3860$

E-mail hjk1000@hallym.or.kr
Background and Objectives The aim of this study was to investigate the surgical outcomes of revision operation due to recurrence of non-cholesteatomatous chronic otitis media (COM) surgery cases.

Subjects and Method From 1989 to 2018, 5197 cases of COM surgery were performed at Kangdong and Hallym University Sacred Heart Hospital. Among them, clinical data of 297 subjects who had undergone revision tympanoplasty and/or mastoidectomy for recurrent noncholesteatomatous COM were retrospectively collected from computerized database of middle ear surgery (Korean Otological Society program 2005). Each case was categorized by surgical approaches into canal wall down mastoidectomy (CWDM), canal wall up mastoidectomy (CWUM), or tympanoplasty only groups.

Results Tympanoplasty only was performed in 170 cases, CWDM in 74 cases, and CMUM in 53 cases. Postoperative perforation occurred in $9.4 \%$ of total cases, and less frequently in CMDM compared with tympanoplasty only ( $p=0.023)$, and CMUM $(p=0.049)$, respectively, whereas no differences between tympanoplasty only and CMUM $(p=0.930)$ were found. Postoperative infection rate was $1.0 \%$ and did not show any differences among the groups. Postoperative successful hearing was obtained in $66.7 \%$ of total cases, and the success rate of tympanoplasty only was better than that of CMDM $(p=0.001)$, and CMUM $(p=0.011)$. And, that of CMUM was better than that of CMDM $(p=0.011)$.

Conclusion The results showed that postoperative perforation occurred less frequently in CMDM than in tympanoplasty only and in CWUM; successful hearing was achieved more frequently in tympanoplasty alone than in the other surgical approaches in recurrent non-cholesteatomatous COM. Korean J Otorhinolaryngol-Head Neck Surg 2021;64(5):304-9

\section{서 론}

이비인후과 외래에서 만성 중이염으로 인한 고막 천공이 있는 경우를 흔히 만나고, 근본적 치료를 위해서 수술적 요법 이 필요하게 된다. 수술의 목적은 천공의 완전한 복구이고, ${ }^{1)}$

This is an Open Access article distributed under the terms of the Creative Commons Attribution Non-Commercial License (https://creativecommons.org/licenses/by-nc/4.0) which permits unrestricted non-commercial use, distribution, and reproduction in any medium, provided the original work is properly cited.
수술 방법에 따라 고막만 재건하는 술기와 유돌절제술과 고 실성형술을 함께 병행하는 술기가 있다.

만성 중이염에서 유돌절제술의 목적은 첫째, 중이점막과 골부의 병변을 제거하여 염증없는 안전한 귀를 유지하는 것 이고, 둘째, 재발 방지를 위해 각 병변의 상태에 알맞은 술식 을 선택하는 것이며, 셋째, 사회적응(socially serviceable) 청 력수준으로 회복하는 것을 ${ }^{2}$ 포함하고, 이러한 목적을 달성하 지 못하였을 경우 재수술이 필요하게 된다. 
유돌절제술 실패의 가장 흔한 원인은 진주종의 재발, 제거 되지 않은 함기봉소의 염증, 그리고 높은 안면신경능(facial ridge)과 불완전한 외이도 성형술(meatoplasty) 때문에 초래 되는 유돌강의 분비물 저류 등이 있다. ${ }^{3)}$ 재발성 중이염은 일 차수술(primary surgery)로서 개방동 유돌절제술보다 폐쇄 동 유돌절제술에서 발생률이 높은 것으로 보고되었고, ${ }^{4-7)}$ 재 수술이 요구되는 재발성 만성 중이염은 형태에 따라 진주종, 함입낭(retraction pocket), 이루가 재발하는 유돌강 및 고막 천공으로 구분되고, 이것은 진주종성과 비진주종성 중이염으 로 분류할 수 있다.

유돌절제술 후 재발한 만성 중이염을 주제로 많은 연구가 현재까지 진행되어 왔으나 ${ }^{8-11}$ 진주종과 비진주종성 중이염 은 병리기전과 임상소견의 차이가 있음에도 불구하고, 재발 한 진주종과 비진주종성 중이염을 구분하여 임상소견과 치 료결과를 비교한 연구는 드문 실정이다.

이에 본 연구에서는 만성 중이염 수술 후 재발한 비진주 종성 중이염에서 임상소견을 조사하고, 재발에 미치는 요인 들을 알아보고자 하였으며 함께 연구된 재발성 진주종성 중 이염의 연구 결과와 비교해 보고자 하였다.

\section{대상 및 방법}

\section{대 상}

1989년 5월 2018년 12월까지 한림대학교 강동성심병원 및 한림대학교성심병원을 내원하여 만성 중이염 진단 하에 수 술적 치료를 받은 환자를 대상으로 수술기록을 포함한 의무 기록 자료와 2005년 대한이과학회(Korean Otological So- ciety, KOS)에서 배포한 중이 수술 데이터베이스 프로그램에 저장/관리된 자료를 이용하여 후향적 분석을 시행하였다. 만 성 중이염 수술 결과에 영향을 미치는 인자를 최소화하기 위해 30년간 단일 술자에 의해 시행된 자료만을 수집하였고, 수술 전후의 청력 개선과 염증 완치의 성공 여부를 결과로서 분석하였다.

연구 기간 동안 같은 병원에서 진주종을 포함한 만성중이 염으로 수술을 받은 예는 5197예이었고, 재수술 받은 예는 그중 621예(12\%)였으며(Fig. 1) 재수술 예 중 비진주종성 중 이염으로 수술 받은 환자는 392예(8\%)였고(Fig. 2), 그중 총 1년 이상 추적 관찰이 가능하였던 297예를 대상으로 임상소 견과 결과를 분석하였다.

모든 대상 환자는 임상적으로 술전 고막 소견 및 전산화 측두골 단층촬영 소견을 참고하여 재발 여부를 판정하였고, 유양돌기부의 함기화(pneumatic)가 잘 되어 있는 함기형의 경우 고실성형술(tympanoplasty)만을 시행하였고, 함기화가 나쁜 판상형(diploic)과 경화형(sclerotic)의 경우에는 유돌절 제술을 병행하였다. 유돌절제술은 개방동 유양돌기 절제술 (canal wall down mastoidectomy, CWDM)과 폐쇄동 유양 돌기 절제술(canal wall up mastoidectomy, CWUM)을 수 술 당시의 질병 상태에 따라서 술식을 선택하여 시행하였다. 또, 술전 고막 소견 및 전산화 측두골 단층촬영(Temporal bone $\mathrm{CT}$ ), 수술 시 병변 소견, 수술 후 조직검사를 바탕으로 임상의 판단 하, 최종 진단을 진주종성이나 비진주종성 중이 염으로 구분하였다.

총 297예 중 남자가 144명이고 여자가 153명으로 여자가 조금 많았으며, 평균 연령은 51.5세였다. 오른쪽 귀가 146명,

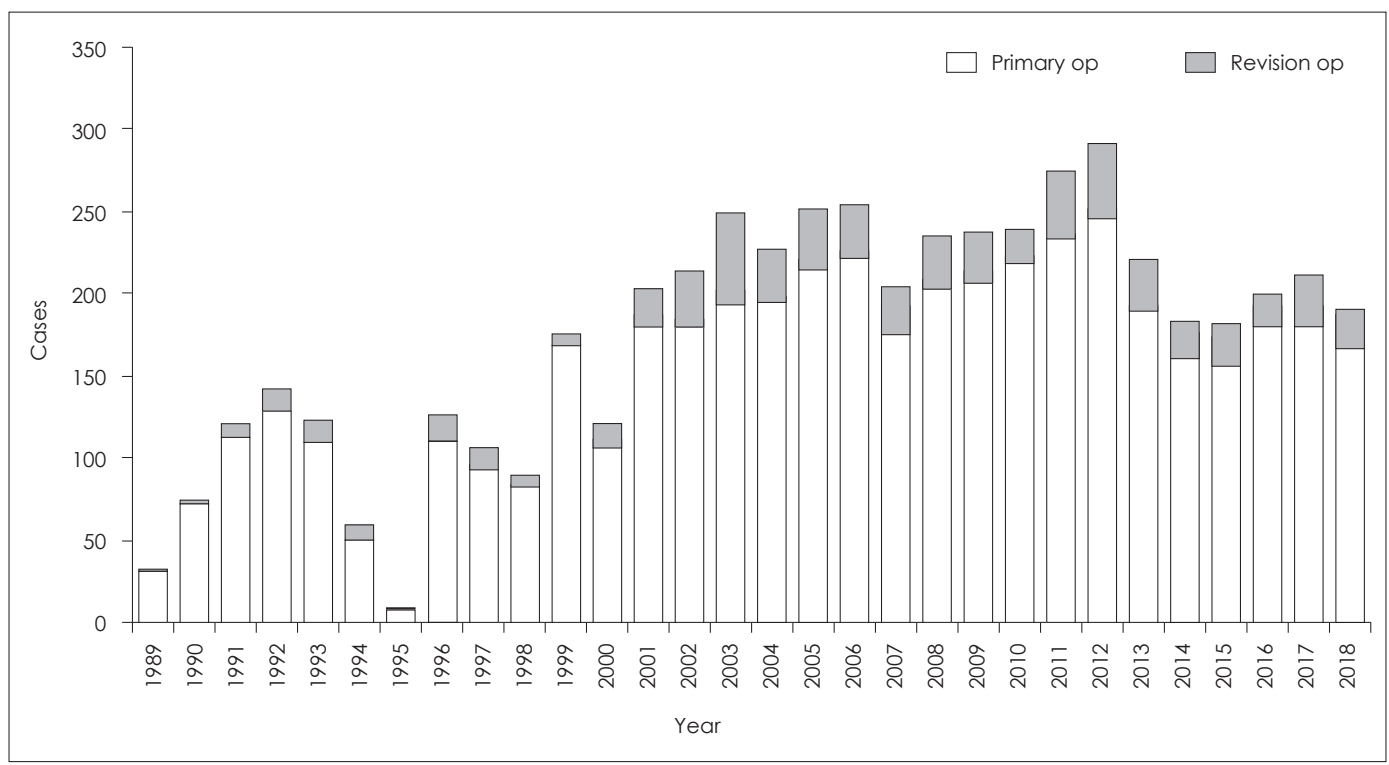

Fig. 1. Number of primary and revision operation per year. op: operation. 


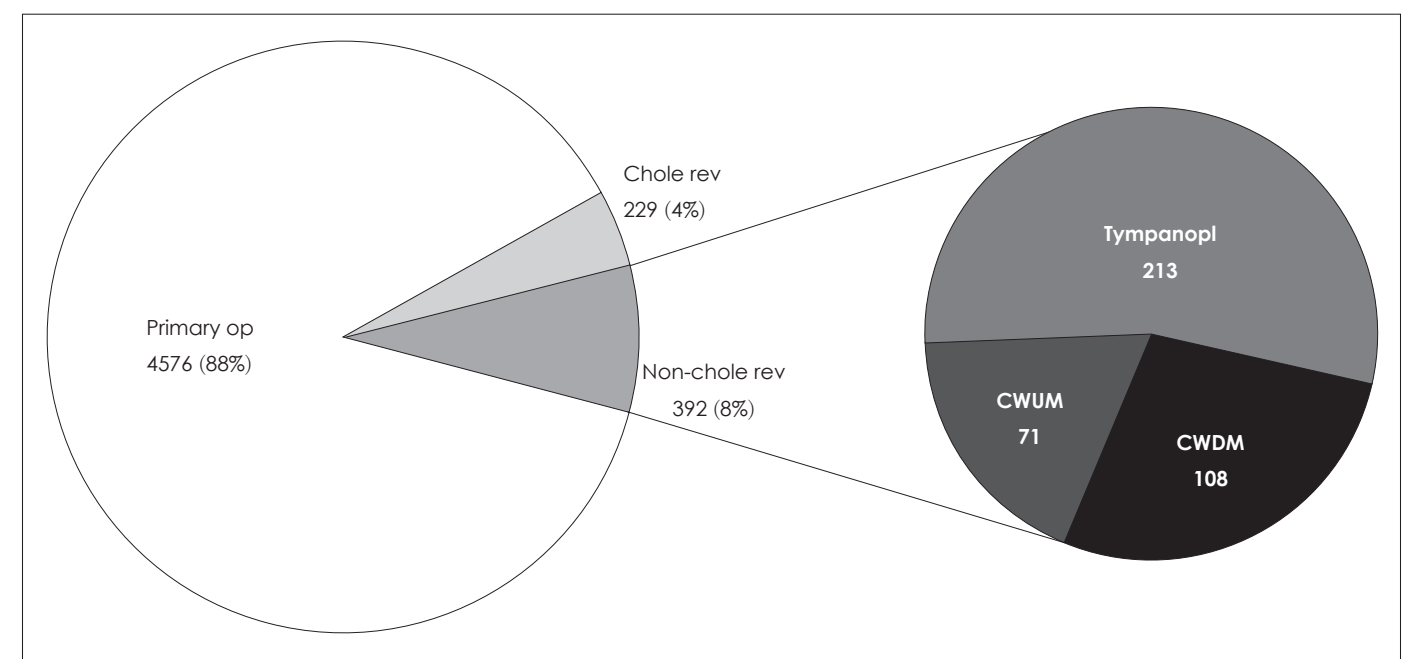

Fig. 2. Subgrouping according to surgical approach on non-cholesteatomatous revision operation. op: operatiom, rev: revision, CWUM: canal wall up mastoidectomy, CWDM: canal wall down mastoidectomy.

왼쪽 귀가 151 명으로 두 군 간에 유의미한 차이는 없었다. $(p>0.05)$ 총 297예 중 2번째 수술은 289예였고, 8명은 3번째 수술이었고, 모든 증례가 이전에 비진주종성 만성 중이염으 로 수술을 받았었다. 사용한 수술 방법으로서 CWUM 53예 (17.8\%), CWDM 74예(24.9\%) 및 tympanoplasty 170예 (57.2\%)로 분포되었다(Table 1).

\section{방 법}

수술 결과로서 수술 후 1 년 이상의 추적 후 청력 개선 정 도와 술후 재발, 즉, 고막 재천공 및 재발성 감염의 발생률을 측정하였고, 그 결과를 수술 전과 후, 수술 방법 간에 비교 분석하였다.

술전 술후 청력 수준은 순음 청력 검사상 기도 청력과 골 도 청력별로 $0.5,1,2$ 및 $3 \mathrm{kHz}$ 의 평균, 즉, 4 분법을 이용하여 평균 역치를 계산하였고, 술후 청력 개선은 6개월 이상 경과 시점의 청력 검사를 이용하였다. 수술 전과 후의 순음 청력 역치와 술후 기도-골도 역치 차(air-bone gap, $\mathrm{ABG}$ )를 비교 하여 개선 정도를 분석하였으며 2005년 KOS에서 제안된 술 후 청력 결과 보고지침 ${ }^{12}$ 에 따라 정리하였다. 즉, 술후 $\mathrm{ABG}$ 가 $20 \mathrm{~dB}$ 이하, 또는 기도 청력 역치(air conduction threshold) 가 $30 \mathrm{~dB}$ 이하, 또는 기도 청력 역치 개선이 $15 \mathrm{~dB}$ 이상인 세 가지 조건 중 하나가 충족되면 "술후 청력 성공(successful hearing)"으로서 평가하였다.

치료 실패는 염증 재발로 정의하였고, 고막 천공, 감염 또는 재발 3가지로 판단하였다. 그중 고막 천공 유무는 술후 3개월 경과 이후에 확인된 경우로 정의하였고, 감염은 술후 지속적 이루, 통증 같은 감염 증세가 조절되지 않아 입원하여 정맥 내 항생제 치료가 필요하였던 경우로 정의하였고, 재발은 술
Table 1. Demographic findings of the study

\begin{tabular}{lc}
\hline Number of patient & 297 \\
Mean age $( \pm S D)$, years & $51.5( \pm 13.8)$ \\
Sex, $\mathrm{n}(\%)(p>0.05)$ & $144(48.5)$ \\
$\quad$ Male & $153(51.5)$ \\
$\quad$ Female & \\
Side, $\mathrm{n}(\%)(p>0.05)$ & $146(49.2)$ \\
$\quad$ Right & $151(50.8)$ \\
Left & \\
Number of surgery, $\mathrm{n}(\%)$ & $289(97.3)$ \\
$\quad$ Second operation & $8(2.7)$ \\
Third operation or more & \\
Surgical procedures, $\mathrm{n}(\%)$ & $53(17.8)$ \\
CWUM & $74(24.9)$ \\
CWDM & $170(57.2)$ \\
Tympanoplasty &
\end{tabular}

SD: standard deviation, CWUM: canal wall up mastoidectomy, CWDM: canal wall down mastoidectomy

후 염증 재발하여 재수술을 받은 경우를 정의하였다.

통계학적 유의성 검사로서 IBM SPSS 23(IBM Corp., Armonk, NY, USA)을 이용한 chi-square test, Wilcoxon signed rank test을 사용하였고, $p$ value는 0.05 미만을 유의수준으 로 판정하였다. 본 연구는 한림대학교 성심병원 임상 연구심 의위원회(IRB)의 연구 승인(HALLYM 2019-09-023-001) 후에 수행되었다.

\section{결 과}

\section{수술 전후 청력 결과}

297명을 대상으로 수술 전후 청력 검사를 분석한 결과, 8.5 
$\pm 12.0 \mathrm{~dB}$ 의 기도 청력 및 $7.9 \pm 11.7 \mathrm{~dB}$ 의 $\mathrm{ABG}$ 가 호전된 것 으로 나타났으나 $(p<0.05)$ 골도 청력의 호전은 관찰되지 않 았다. 술전 기도 청력의 평균은 $49.7 \pm 21.9 \mathrm{~dB}$ 였고, 술후 기도 청력 평균은 $41.2 \pm 24.6 \mathrm{~dB}$ 였으며, 술전 $\mathrm{ABG}$ 는 $26.1 \pm 13.0$ $\mathrm{dB}$ 였고, 술후 $\mathrm{ABG}$ 는 $18.2 \pm 13.1 \mathrm{~dB}$ 로 수술 후에 유의미하 게 호전된 것으로 측정되었다 $(p<0.05)$ (Fig. 3).

술후 성공적인 청력의 기준에 따라서, 술후 $\mathrm{ABG}$ 가 $20 \mathrm{~dB}$ 이하였던 예는 총 297예 중 181예(61\%)였고, 술후 기도 청력이 $30 \mathrm{~dB}$ 이하였던 예는 119 예(40\%)였으며, 술후 청력 개선이 $15 \mathrm{~dB}$ 이상인 경우는 74 예(25\%)로 측정되었다.

\section{수술 방법에 따른 청력 결과}

총 74예에서 CWDM을 시행하였고, 그중 32예(43\%)에서 술후 성공적인 청력을 보였고, 총 53예에서 CWUM을 시행 하였고, 그중 35예(66\%)에서 술후 성공적인 청력을 보였으며 총 170예에서 고실성형술만을 시행하였고, 그중에 131예 (77\%)에서 술후 성공적인 청력을 보였다. 전체적으로 재발된 비진주종성 만성 중이염 수술 총 297예 중 198예(67\%)에서 술후 성공적인 청력을 보였다(Fig. 4).

\section{청력 이외의 수술 결과}

총 297예 중 260예(88\%)에서 염증 완치 군(disease control rate)에 속하였고, 나머지 37예(12\%)에서 고막 천공, 감염 또는 재발의 소견이 보였고, 고막 재천공이 28예(9\%)로 가장 많았다(Table 2). 수술 방법에 따라 구분하였을 때 CWDM 에서 2예(2.7\%)로 CWUM의 6예(11.3\%)나 고실성형술 군의 20예(11.8\%)에 비해서 고막 재천공 비율이 유의하게 낮았다. $(p<0.05)$ 염증 재발률(treatment failure rate)로 보았을 때도

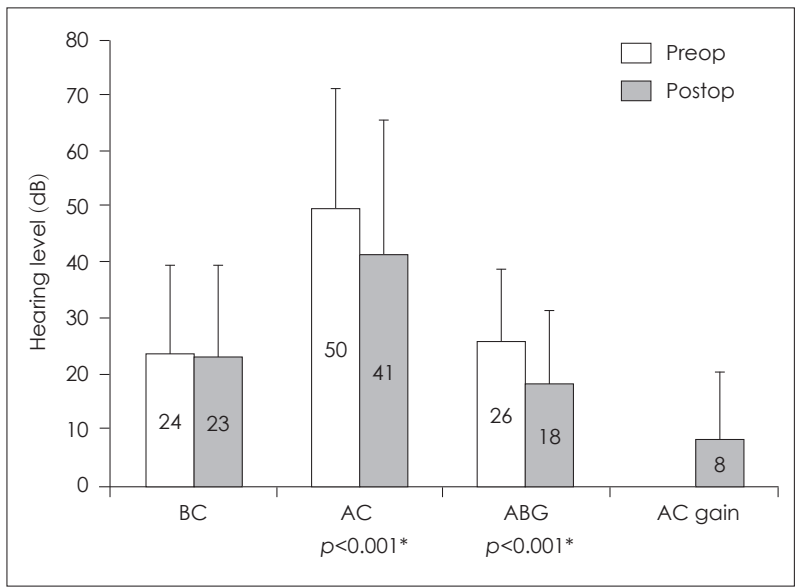

Fig. 3. Preoperative and postoperative hearing level and ABG, and postoperative air conduction gain. ${ }^{*} p<0.05$. Preop: pre-operation, Postop: post-operation, BC: bone conduction, AC: air conduction, ABG: air-bone gap.
CWDM에서 2예(2.7\%)로 마찬가지로 CWUM의 8예(15.1\%) 나 고실성형술 군의 27예(15.9\%)에 비해 유의하게 낮았다 $(p$ $<0.05)$.

\section{고 찰}

고실성형술은 중이강 내의 비가역적 병변을 제거하고, 청 력을 개선하는데 목적이 있고, 수술의 방법은 일반적으로 고 막과 이소골의 상태에 따라 분류한다. ${ }^{13)}$ 이소골의 연쇄가 정 상 상태일 경우 고막을 재건하는 제1형 고실성형술의 경우

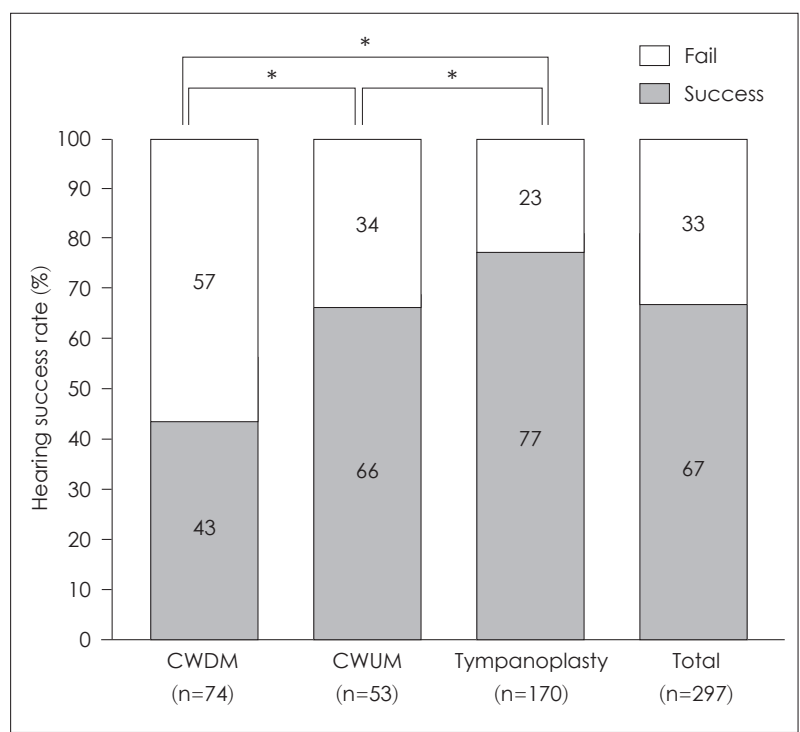

Fig. 4. Hearing success rate according to surgical approach. ${ }^{*} p<0.05$.

Table 2. Outcomes of non-cholesteatomatous COM and cholesteatomatous revision surgery ${ }^{20)}$

\begin{tabular}{|c|c|c|}
\hline & $\begin{array}{c}\text { Non-cholesteatomatous } \\
\text { COM }\end{array}$ & Cholesteatoma $^{20)}$ \\
\hline \multicolumn{3}{|c|}{ Successful hearing rate (\%) } \\
\hline$A$ & $181 / 297(61)$ & $59 / 138(43)$ \\
\hline B & $119 / 297(40)$ & $30 / 138(22)$ \\
\hline C & $74 / 297(25)$ & $27 / 138(20)$ \\
\hline $\begin{array}{l}\text { At least } 1 \\
\text { criteria }\end{array}$ & 198/297 (67) & $70 / 138(51)$ \\
\hline $\begin{array}{l}\text { Disease control } \\
\text { rate }(\%)\end{array}$ & 260/297 (88) & 122/138 (88) \\
\hline \multicolumn{3}{|c|}{ Treatment failure rate (\%) } \\
\hline Perforation & $28(9)$ & $6(4)$ \\
\hline Infection & $3(1)$ & $5(4)$ \\
\hline Recurrence & $8(3)$ & $5(4)$ \\
\hline
\end{tabular}

A: postoperative air-bone gap $\leq 20 \mathrm{~dB}, \mathrm{~B}$ : postoperative $\mathrm{AC}$ PTA's $\leq 30 \mathrm{~dB}, \mathrm{C}$ : hearing gain (preop AC PTA's-postop. AC PTA's) $\geq 15 \mathrm{~dB}, \mathrm{COM}$ : chronic otitis media, PTA: pure tone audiometry 
청력의 개선 정도는 약 $10 \mathrm{~dB}$ 이며, 수술 후 76 80\%에서 성 공적인 청력 결과를 보인다고 하였다. ${ }^{14-16)}$ 본 연구에서도 $84 \%$ 에서 성공적인 청력을 보여 이전의 연구들과 유사한 결 과를 나타내고 있다.

만성 중이염 재수술에서의 청력 결과에 영향을 주는 중요 한 요인 중 하나로 외이도 후벽의 보존이 알려져 있다. 2,17) Veldman과 Braunius ${ }^{2}$ 는 CWUM을 시행한 예의 $65 \%$ 에서 $30 \mathrm{~dB}$ 이하의 $\mathrm{ABG}$ 를 보였으나 CWDM에서는 $48 \%$ 로 낮게 보고하였고, Kaylie 등 ${ }^{17)}$ 도 CWUM 예의 $73.4 \%$ 에서 $30 \mathrm{~dB}$ 이하의 $\mathrm{ABG}$ 를 보였으나 $\mathrm{CWDM}$ 환자에서는 $61.6 \%$ 로 낮은 결과를 보고하였다. 본 연구에서는 $2005 \mathrm{KOS}$ 청력 결과 보 고지침에 따라 $\mathrm{CWDM}$ 에서는 $43 \%, \mathrm{CWUM}$ 에서는 $66 \%$ 에 서 성공적인 청력 결과를 얻었고, 이는 이전의 연구 결과에 비해 청력 개선은 다소 낮으나 CWUM이 CWDM보다 술후 청력 결과가 좋다는 점은 일치하였다. 일반적으로 병변이 심 하지 않은 경우에 CWUM을 시행하는 경향이 있으므로 병 변이 보다 심한 CWDM과 청력 결과를 단순 비교하기는 어렵 지만 좀 더 좋은 청력 결과를 위해서는 CWUM을 선택하는 것을 고려해 볼 수 있다.

본 연구에서 수술 후 성공적인 청력 결과를 보인 예는 전 체의 $67 \%$ 이고, 고실성형술만 시행한 예는 그중 $77 \%$ 로 나타 났다. 이는 이전에 일차수술 청력 결과 연구에서 보고된 76 $80 \% \%^{5-7)}$ 의 성공률보다 낮았는데, 그 이유는 일차수술군에 비 해 재수술에서 추골과 등골의 손상이 상대적으로 많았고, 재발한 경우 보통 이관 기능이 더 불량하여 충분한 중고실 공간의 확보가 어렵고, 이로 인해 이식물(cartilage or artificial prosthesis)이 안정적으로 유지될 수 없었기 때문이라고 추측할 수 있다. 다만, 본 연구에서 재수술에서의 이관 기능 과 중고실의 함기화에 대해서 시행하지 않았으므로 향후 추 가 연구가 필요할 것이다.

유돌절제술은 중이 내 압력변화에 대한 완충작용을 할 수 있는 공기를 보유한 공간을 만들고, 유양동 내에 숨어 있는 염증성 점막 병변을 제거하여 재발을 방지하는 역할을 해야 한다. ${ }^{18)}$ 한편, 재수술이 필요한 재발성 만성 중이염은 개방동 유양돌기 절제술(CWDM) 후에는 3 18\%에서 재발되고, ${ }^{4,5)}$ 폐쇄동 유양돌기 절제술(CWUM) 후에는 11 34\%에서 재발 하였다고 보고되고 있다. ${ }^{6.7)}$ 본 연구에서는 $88 \%$ 에서 염증이 완치되어 깨끗한 귀를 얻을 수 있었고, $12 \%$ 에서 고막 천공, 감염, 또는 진주종 재발이 발생하였으며, 이는 이전에 발표했 던 Veldman과 Braunius ${ }^{2)}$ 그리고 $\mathrm{Nadol}^{19}$ 의 문헌과 비교하 였을 때 만족할 만한 결과이다. $\mathrm{Nadol}^{19}$ ) 은 66 명의 재수술 환 자 모두에서 CWDM과 함께 외이도 성형술, 유양돌기 폐쇄술 (mastoid obliteration), 높은 안면신경 능의 제거를 시행하여
$85 \%$ 의 완치율을 보고하였다. 본 연구 결과에서 $88 \%$ 의 염증이 완치된 예 중에서 CWDM가 $97 \%$ 로 고실성형술이나 CWUM 에 비하여, 치료 성적이 좋았다. 고막의 재천공률 역시 마찬가 지로, $\mathrm{CWDM}$ 에서 $3 \%$ 로 $\mathrm{CWUM}$ 에서의 $11 \%$ 에 비해 성적이 좋았다.

본 연구와 더불어 같은 모집단을 대상으로 동일한 연구 방 법을 적용하여 분석한 별개의 연구인 재발한 진주종성 중이 염의 재수술에 대한 결과 ${ }^{20}$ 와의 비교를 해보았을 때, 진주종 성 중이염에서는 수술 전 골도 청력 수치는 $23.8 \pm 18.5 \mathrm{~dB}$ 로 비진주종성 중이염의 $23.7 \pm 16.2 \mathrm{~dB}$ 와 거의 유사하였고, 마 찬가지로 골도 청력의 호전은 관찰되지 않았다. 기도 청력의 경우 수술 전 $52.1 \pm 23.5 \mathrm{~dB}$, 수술 후 기도 청력 $48.1 \pm 24.7 \mathrm{~dB}$ 로 수술 후에 $4 \pm 13.7 \mathrm{~dB}$ 만큼 호전되었고, 이는 앞서 기술한 비진주종성 중이염의 술후 청력 호전 정도보다 좋지 않았다. 또한, 133예 중에 70예(51\%)에서 술후 성공적인 청력으로 관 찰되어 이 역시 비진주종성 중이염의 술후 청력 성공률(67\%) 에 비해 좋지 않았다(Table 2). 이는 진주종은 병의 진행에 따라 다르겠지만, 이소골 침식 등 중이의 구조물을 파괴하고, 고막 이완부 근처의 종괴 형성으로 인해 외이도 침식 등의 골 파괴를 동반하는 특징 ${ }^{21)}$ 을 가지기 때문으로 생각된다. 또 한, 진주종성 중이염에는 CWDM가 133예(58\%)로 대다수를 차지했다는 점도 낮은 청력 개선도에 기여할 수 있었다. 한편, 염증 완치율에 있어서는 진주종성 중이염, 비진주종성 중이 염 모두에서 88\%의 비슷한 결과를 얻었다(Table 2). 이는 비 진주종성 중이염의 경우 기존의 알려진 바와 비슷한 수준이 었으나, ${ }^{2,19,22)}$ 진주종성 중이염에 대해서는 기존의 재발률로 알려진 $17 \%$ 에 비하여, ${ }^{23)} 12 \%$ 의 비교적 좋은 성적을 얻었다.

본 연구 결과에서의 제한점은 첫째, 후향적 연구로써 미비 자료가 많고 청력 결과 추적 기간이 짧았다는 점이며, 둘째, 연구 대상의 규모가 크지 않아 술전 고막 천공의 크기, 이소 골의 손상 여부, 부대 술기 여부 등 재발에 영향을 줄 수 있 는 다른 예후 인자를 조사하지 못한 점을 들 수 있다. 추후에 전향적 연구를 통해 보완된 후속 연구와 타 기관 공동연구 를 통해 다른 예후 인자들을 보정할 필요가 있을 것이다.

요약하면 297예의 비진주종성 만성 중이염 재수술에서 청 력 개선 성공률은 $67 \%$ 였고, 염증 완치율은 $88 \%$ 로 측정되었 으며, 재수술 중 9\%의 고막 재천공률을 포함한 $12 \%$ 의 염증 재발률에도 불구하고 술후 청력 호전에는 도움이 되는 것으 로 나타났고, 이 자료는 술전 상담 시 수술 예후 판정의 참고 자료로 활용할 수 있을 것이다.

\section{Acknowledgments}

This study was supported by the National Research Foundation of Korea (NRF) grant funded by the Korean Government (2018 


\section{R1D1A1B07045305).}

\section{Author Contribution}

Conceptualization: Hyung-Jong Kim. Data curation: Juho Han. Formal analysis: Jisoo Lee. Project administration: Sung Kwang Hong. Supervision: Hyo Jeong Lee. Writing—original draft: Juho Han. Writing — review \& editing: Hyung-Jong Kim.

\section{ORCIDs}

Hyung-Jong Kim

https://orcid.org/0000-0001-9020-6026

JuHo Han

\section{REFERENCES}

1) Aggarwal R, Saeed SR, Green KJ. Myringoplasty. J Laryngol Otol 2006;120(6):429-32.

2) Veldman JE, Braunius WW. Revision surgery for chronic otitis media: A learning experience. Report on 389 cases with a longterm follow-up. Ann Otol Rhinol Laryngol 1998;107(6):486-91.

3) Cody DT, McDonald TJ. Mastoidectomy for acquired cholesteatoma: Follow-up to 20 years. Laryngoscope 1984;94(8):1027-30.

4) Ohrt HH. On recurrence in cavities after radical mastoidectomy with special reference to the complications which may arise. Acta Otolaryngol 1957;47(4):346-52.

5) Jepsen O, Zwergius E. The cavities after retro-auricular radical ear operations with special reference to the significance of the primary factor. Acta Otolaryngol 1951;39(5):388-94.

6) Sheehy JL, Brackmann DE, Graham MD. Cholesteatoma surgery: Residual and recurrent disease. A review of 1,024 cases. Ann Otol Rhinol Laryngol 1977;86(4 Pt 1):451-62.

7) Smyth GD. Postoperative cholesteatoma in combined approach tympanoplasty. Fifteen year report on tympanoplasty. Part I. J Laryngol Otol 1976;90(7):597-621.

8) Kasenõmm P. Intraoperative findings of revision canal wall-down tympanomastoid surgery. Acta Otolaryngol 2013;133(8):826-32.

9) Li S, Meng J, Zhang F, Li X, Qin Z. Revision surgery for canal wall down mastoidectomy: Intra-operative findings and results.

Acta Otolaryngol 2016;136(1):18-22.

10) Košec A, Kelava I, Ajduk J, Ries M, Trotić R, Bedeković V. Significance of intraoperative findings in revision tympanomastoidectomy. Am J Otolaryngol 2017;38(4):462-5.

11) Cho YS, Hong SD, Chung KW, Hong SH, Chung WH, Park SH. Revision surgery for chronic otitis media: Characteristics and outcomes in comparison with primary surgery. Auris Nasus Larynx 2010;37(1):18-22.

12) Kim HJ. Classification and hearing result reporting guideline in chronic otitis media surgery. Korean J Otolaryngol-Head Neck Surg 2006;49(1):2-6.

13) Wullstein $\mathrm{H}$. Theory and practice of tympanoplasty. Laryngoscope 1956;66(8):1076-93.

14) Cody DT, Taylor WF. Tympanoplasty: Long-term results. Ann Otol Rhinol Laryngol 1973;82(4):538-46.

15) Claes J, Van de Heyning PH, Creten W, Koekelkoren E, Van Laer C, De Saegher D, et al. Allograft tympanoplasty: Predictive value of preoperative status. Laryngoscope 1990;100(12):1313-8.

16) Gerber MJ, Mason JC, Lambert PR. Hearing results after primary cartilage tympanoplasty. Laryngoscope 2000;110(12):1994-9.

17) Kaylie DM, Gardner EK, Jackson CG. Revision chronic ear surgery. Otolaryngol Head Neck Surg 2006;134(3):443-50.

18) Ruhl CM, Pensak ML. Role of aerating mastoidectomy in noncholesteatomatous chronic otitis media. Laryngoscope 1999; 109(12):1924-7.

19) Nadol JB Jr. Causes of failure of mastoidectomy for chronic otitis media. Laryngoscope 1985;95(4):410-3.

20) Lee JS, Han JH, Hong SK, Lee HJ, Kim HJ. Surgical outcome of revision operation for recurrent aural cholesteatoma. Korean J Otorhinolaryngol-Head Neck Surg 2021;64(3):148-54.

21) Chang JA, Rho MH, Kim YM, Lee HS, Choi PY, Jung KS, et al. Temporal bone CT findings of tuberculous otitis media: Comparison with chronic otitis media. J Korean Radiol Soc 1999;40(6):1063-9.

22) Tos M, Lau T. Revision tympanoplasty. J Laryngol Otol 1986; 100(10):1097-105.

23) Edelstein DR, Parisier SC. Surgical techniques and recidivism in cholesteatoma. Otolaryngol Clin North Am 1989;22(5):1029-40. 